\title{
Preparation and Crystallization Property of Ternary Composites of WBG/AA-RCC/PP
}

\author{
Jiang Zhu, ${ }^{1}$ Haitao $\mathrm{Ni}^{2}{ }^{2}$ Xiaoqing Liao, ${ }^{2}$ and Xiang Liu ${ }^{2}$ \\ ${ }^{1}$ Chongqing Key Laboratory of Environmental Materials and Remediation Technologies, Chongqing University of Arts and Sciences, \\ Yongchuan, Chongqing 402160, China \\ ${ }^{2}$ College of Materials and Chemical Engineering, Chongqing University of Arts and Sciences, Yongchuan, Chongqing 402160, China
}

Correspondence should be addressed to Haitao Ni; htniok@163.com

Received 17 September 2015; Revised 20 October 2015; Accepted 21 October 2015

Academic Editor: Ewa Schab-Balcerzak

Copyright (C) 2015 Jiang Zhu et al. This is an open access article distributed under the Creative Commons Attribution License, which permits unrestricted use, distribution, and reproduction in any medium, provided the original work is properly cited.

A series of ternary composites of WBG/AA-RCC/PP were prepared and their crystallization behaviors were investigated by XRD and DSC. The results indicate that WBG and AA-RCC affect the crystallization of PP matrix with a mutual inhibition effect. This effect is enhanced with increasing content of WBG and induces the growth of $\beta_{2}$ crystal. AA-RCC promotes the heterogeneous nucleation of $\alpha$ crystal and offers a template for $\alpha$ crystal growth along a specific lattice plane and promotes the epitaxial crystallization of PP matrix, while the specific arranged $\alpha$ crystal could induce the formation of $\beta$ crystal.

\section{Introduction}

Polypropylene (PP) is a kind of commercial polymers with good performance. However, some defects such as low notch impact strength and low-temperature brittleness restrict further application of PP. Because of this reason, some fillers or reinforcements have been introduced in order to develop PP composite with desired properties [1-10]. $\mathrm{CaCO}_{3}$ is among the most frequently studied objects in modification research. As a typical rigid particle, $\mathrm{CaCO}_{3}$ does indeed play an important role in performance improvement of PP. In particular, with the development of powder technology, the use of nanoscale $\mathrm{CaCO}_{3}$ particles has received much attention for polymer-based nanocomposites. Compared to conventional microcomposites, the addition of $\mathrm{CaCO}_{3}$ nanoparticles can ameliorate the mechanical, thermal, and wear properties of thermoplastics [6-10]. However, there is still dearth of some data about the influence of the $\mathrm{CaCO}_{3}$ nanoparticles with different shapes (rhombohedral or spherical) on crystallization behavior of the nanocomposites.

At present, the PP modification products are emerging. Nevertheless, there are deficiencies in each product, which need to be improved. Studies have shown that $\beta$-nucleated PP has excellent impact resistance and creep resistance. However, the development and study of $\beta$ nucleating agent are far less than those of $\alpha$ nucleating agent. The research on new nucleating agent and compound modification system deserves attention.

\section{Materials and Methods}

2.1. Material. The isotactic polypropylene T30S with a melt flow index of $2.6 \mathrm{~g} / 10 \mathrm{~min}$ was supplied by Lanzhou Petrochemical Company (China National Petroleum Corporation). The rhombohedra $\mathrm{CaCO}_{3}$ was provided by Nano Materials Technology Co., Ltd., (Ruicheng, Shanxi, China), which will be denoted as "RCC" throughout the paper. The rare earth $\beta$ nucleating agent (WBG) was provided by Guangdong Winner New Materials Technology Co., Ltd. (WINNER). The adipic acid was provided by Chengdu Kelong Chemical Co., Ltd. All other materials were of analytical grade and used without further purification. Water was distilled and deionized.

2.2. Surface Treatment of the $\mathrm{CaCO}_{3}$ Particles. To improve the interfacial adhesion between the filler and the polymer matrix, $\mathrm{CaCO}_{3}$ nanopowders were coated with $8 \mathrm{wt} \%$ adipic acid, which will be denoted as "AA-RCC" throughout the paper. The coating method was as follows. Firstly, $15 \mathrm{~g}$ of RCC was put into the single-neck flask and mixed with a $60 \mathrm{~mL}$ 
TABLE 1: The compositions of composites (weight ration).

\begin{tabular}{lccc}
\hline Samples & AA-RCC $(\mathrm{g})$ & WBG $(\mathrm{g})$ & PP $(\mathrm{g})$ \\
\hline $1-1$ & 0 & 0.2 & 100 \\
$1-2$ & 2 & 0.2 & 98 \\
$1-3$ & 4 & 0.2 & 96 \\
$1-4$ & 6 & 0.2 & 94 \\
$2-1$ & 4 & 0 & 96 \\
$2-2$ & 4 & 0.1 & 96 \\
$2-3$ & 4 & 0.2 & 96 \\
$2-4$ & 4 & 0.3 & 96 \\
$2-5$ & 4 & 0.4 & 96 \\
\hline
\end{tabular}

solution mixture of water and ethanol with a volume ratio of $3: 1$. And then the system was maintained at $80^{\circ} \mathrm{C}$ with a magnetic stirrer for $2 \mathrm{~h}$. Finally, the product was dried in an oven at $90^{\circ} \mathrm{C}$ for $24 \mathrm{~h} \mathrm{[10]}$.

2.3. Preparation of the Composites. The composition of the composites used in the experiments is listed in Table 1. Before mixing, the pure PP and two fillers (AA-RCC and WBG) were dried at $100^{\circ} \mathrm{C}$ for $2 \mathrm{~h}$. The mixtures were compounded in a single-screw extruder. The rate of the screw was $60 \mathrm{rpm}$. The temperature of the extruder from the hopper to the die was set at $195^{\circ} \mathrm{C}, 200^{\circ} \mathrm{C}$, and $200^{\circ} \mathrm{C}$, respectively.

2.4. Characterization. Wide-angle X-ray diffraction (WXRD) analyses were performed on an XRD-6000 diffractometer (Shimadzu, Japan) with an X-ray generator of $3 \mathrm{~kW}$, graphite monochromatic, and $\mathrm{Cu} \mathrm{K} \alpha$ radiation (wavelength $=1.5406 \AA$ ) and were operated at $40 \mathrm{kV}$ and $20 \mathrm{~mA}$. The samples were scanned at room temperature from $10^{\circ}$ to $50^{\circ}$ at a scanning rate of $2^{\circ} / \mathrm{min}$. The content of the $\beta$-crystal in the crystalline part was calculated according to the standard procedures as follows [1]:

$$
\begin{aligned}
K_{\beta 1} & =\frac{H_{\beta}(300)}{H_{\beta}(300)+H_{\alpha}(110)+H_{\alpha}(040)+H_{\alpha}(130)}, \\
K_{\beta 2} & =\frac{H_{\beta}(301)}{H_{\beta}(301)+H_{\beta}(300)},
\end{aligned}
$$

where $H_{X}(h k l)$ denotes the intensity of respective $(h k l)$ peak belonging to phase $X$.

The crystallization behavior of PP composites was studied by DSC Q2000 (TA Instruments, USA). For nonisothermal crystallization, the samples were first treated isothermally at $200^{\circ} \mathrm{C}$ for $3 \mathrm{~min}$ to erase previous thermal history and quenched to $20^{\circ} \mathrm{C}$, then heated up to $200^{\circ} \mathrm{C}$ at $10^{\circ} \mathrm{C} / \mathrm{min}$, held at $200^{\circ} \mathrm{C}$ for $1 \mathrm{~min}$, and cooled to $20^{\circ} \mathrm{C}$ at the constant cooling rates $10^{\circ} \mathrm{C} / \mathrm{min}$. The endothermic and exothermal traces were recorded for the later data analysis. All measurements were
TABLE 2: The content of the $\beta$-crystal with dfferent measurement methods.

\begin{tabular}{lccccc}
\hline Samples & $K_{\beta 1}$ & $K_{\beta 2}$ & $X_{\beta 1}$ & $X_{\beta 2}$ & $X_{\alpha}$ \\
\hline $1-1$ & 0.87 & 0.26 & $/$ & 0.38 & 0.06 \\
$1-2$ & 0.63 & 0.36 & 0.11 & 0.02 & 0.22 \\
$1-3$ & 0.55 & 0.63 & 0.54 & 0.12 & 0.06 \\
$1-4$ & 0.72 & 0.58 & 0.58 & 0.12 & 0.06 \\
$2-1$ & $/$ & $/$ & $/$ & $/$ & 0.56 \\
$2-2$ & 0.70 & 0.57 & 0.55 & 0.13 & 0.06 \\
$2-3$ & 0.55 & 0.63 & 0.54 & 0.11 & 0.06 \\
$2-4$ & 0.52 & 0.85 & 0.73 & 0.05 & 0.06 \\
$2-5$ & 0.49 & 0.84 & 0.68 & 0.03 & 0.06 \\
\hline
\end{tabular}

carried out at the nitrogen atmosphere environment. The crystalline $\left(S_{\beta}\right)$ of the composites is calculated with

$$
\begin{aligned}
& X_{\alpha}=\frac{\Delta H_{f}^{\alpha}}{\Delta H_{f}^{1}}, \\
& X_{\beta}=\frac{\Delta H_{f}^{\beta}}{\Delta H_{f}^{2}} .
\end{aligned}
$$

Here $\Delta H_{f}{ }^{\alpha}$ and $\Delta H_{f}{ }^{\beta}$ are the fusion heat of $\alpha$ and $\beta$ crystal from DSC thermograms, respectively. $\Delta H_{f}{ }^{1}$ is the perfect $\alpha$ crystal fusion heat of the hypothetically $100 \%$ crystalline PP $\left(177 \mathrm{~J} / \mathrm{g}\right.$ ), and $\Delta H_{f}{ }^{2}$ is the perfect $\beta$ crystal fusion heat of the hypothetically $100 \%$ crystalline PP $(168.5 \mathrm{~J} / \mathrm{g})$ [11].

Polarized optical microscopy (POM) studies were carried out with an ECLIPSE LV100POL microscope (Nikon, Japan) in conjunction with a HSC621 V hot stage (Instec, USA). The specimens were heated to $230^{\circ} \mathrm{C}$ on a hot stage and held at this temperature for $3 \mathrm{~min}$ to eliminate the thermal history and then quenched to the fixed crystallization temperature $\left(130^{\circ} \mathrm{C}\right)$. The photographs were provided by a digital camera.

\section{Results and Discussion}

3.1. Wide-Angle X-Ray Diffraction Analysis. Figures 1 and 2 show the XRD patterns of composites and the $K_{\beta}$ values calculated according to (1) are listed in Table 2. It is clear that the main diffraction peaks are at $2 \theta=14.1^{\circ}, 16.9^{\circ}$, and $18.6^{\circ}$, which are attributed to the reflections of (110), (040), and (130) lattice planes, respectively. The peaks at $2 \theta=16.1$ and $21.3^{\circ}$ are assigned to (300) lattice plane of $\beta_{1}$ crystal and (301) lattice plane of $\beta_{2}$ crystal, respectively. According to the XRD curve $1-1$, the strongest diffraction peak is at $2 \theta=16.1^{\circ}$ and assigned to (300) lattice plane of $\beta_{1}$ crystal. The XRD results show that the content of $\beta$-crystal is 0.87 when the WBG addition content is $0.2 \mathrm{phr}$, which is in accord with previous report [12]. As seen at 2-1 line for $4 \mathrm{phr}$ AA-RCC/PP, the strongest diffraction peak is at $2 \theta=16.9^{\circ}$ and assigned to (040) lattice plane of $\alpha$ crystal. It can be concluded that, with addition of WBG or AA-RCC, composites crystalize along a specific lattice plane and orientation. Therefore, WBG acts as a kind of $\beta$-crystal nucleating agent, while AA-RCC acts as a kind of $\alpha$-crystal nucleating agent. 
TABLE 3: Nonisothermal crystallization kinetics parameters of WBG/AA-RCC/PP.

\begin{tabular}{ccccccccccc}
\hline & $\begin{array}{c}T_{c}{ }^{\beta} \\
\left({ }^{\circ} \mathrm{C}\right)\end{array}$ & $\begin{array}{c}\Delta H_{c}{ }^{\beta} \\
(\mathrm{J} / \mathrm{g})\end{array}$ & $\begin{array}{c}T_{c}{ }^{\alpha} \\
\left({ }^{\circ} \mathrm{C}\right)\end{array}$ & $\begin{array}{c}\Delta H_{c}{ }^{\alpha} \\
(\mathrm{J} / \mathrm{g})\end{array}$ & $\begin{array}{c}T_{m}{ }^{\beta} \\
\left({ }^{\circ} \mathrm{C}\right)\end{array}$ & $\begin{array}{c}\Delta H_{m}{ }^{\beta 1} \\
(\mathrm{~J} / \mathrm{g})\end{array}$ & $\begin{array}{c}T_{m}{ }^{\beta 2} \\
\left({ }^{\circ} \mathrm{C}\right)\end{array}$ & $\begin{array}{c}\Delta H_{m}{ }^{\beta 2} \\
(\mathrm{~J} / \mathrm{g})\end{array}$ & $\begin{array}{c}T_{m}{ }^{\alpha} \\
\left({ }^{\circ} \mathrm{C}\right)\end{array}$ & $\begin{array}{c}\Delta H_{m}{ }^{\alpha} \\
(\mathrm{J} / \mathrm{g})\end{array}$ \\
\hline $1-1$ & $/$ & $/$ & 126.81 & 73.92 & $/$ & $/$ & 152.38 & 64.22 & 167.23 & 10.06 \\
$1-2$ & 120.36 & 98.17 & $/$ & $/$ & 128.76 & 18.34 & 146.65 & 4.23 & 160.77 & 38.68 \\
$1-3$ & 118.58 & 89.30 & 126.74 & 30.70 & 131.13 & 90.87 & 149.52 & 19.58 & 162.49 & 9.96 \\
$1-4$ & 118.41 & 90.78 & 126.84 & 28.11 & 131.07 & 97.02 & 149.56 & 19.74 & 162.70 & 10.00 \\
$2-1$ & $/$ & $/$ & 123.89 & 100.40 & $/$ & $/$ & $/$ & 1 & 161.78 & 99.93 \\
$2-2$ & 118.52 & 86.09 & 126.61 & 31.68 & 130.85 & 93.00 & 149.14 & 21.93 & 162.41 & 11.15 \\
$2-3$ & 118.58 & 89.30 & 126.74 & 30.70 & 131.13 & 90.87 & 149.52 & 19.58 & 162.49 & 9.96 \\
$2-4$ & 118.48 & 127.50 & 126.94 & 5.95 & 130.84 & 122.80 & 148.58 & 8.74 & 161.85 & 9.90 \\
$2-5$ & 118.54 & 121.1 & $/$ & $/$ & 130.92 & 114.20 & 147.47 & 5.95 & 160.39 & 11.25 \\
\hline
\end{tabular}

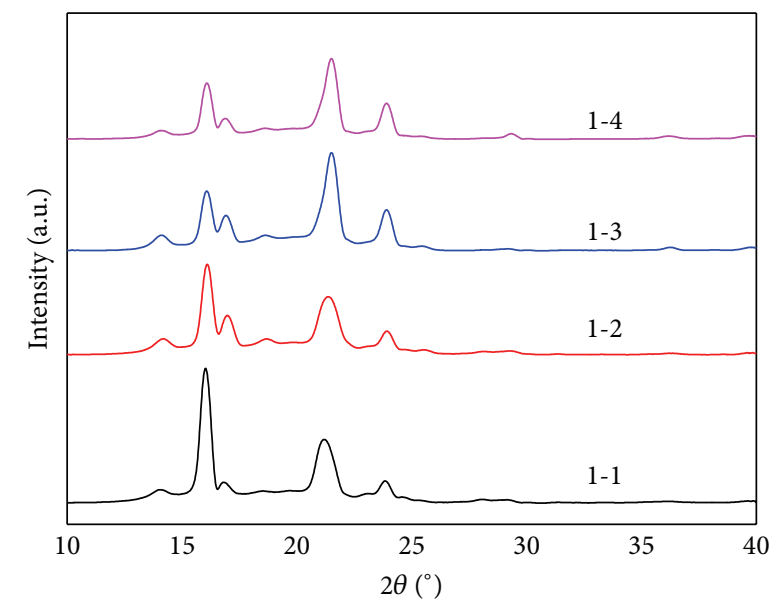

FIGURE 1: WAXD spectra of PP with the different AA-RCC content.

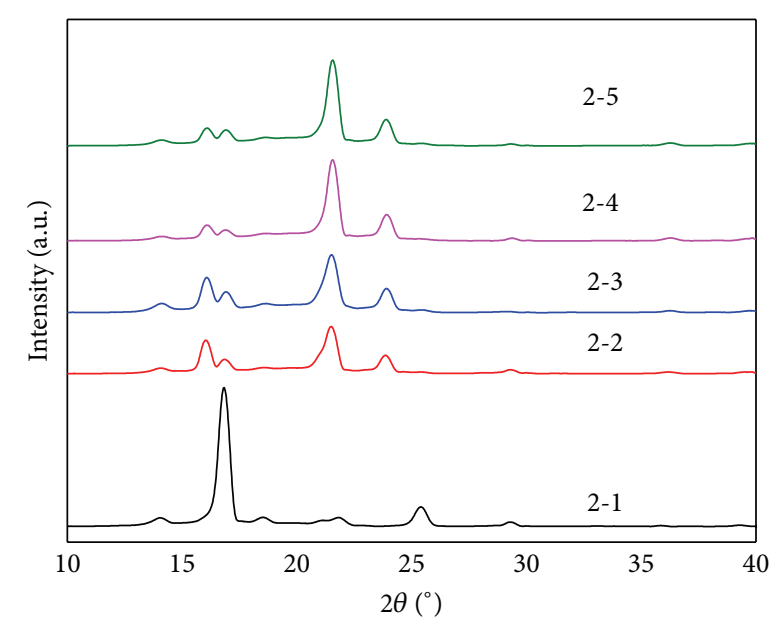

FIGURE 2: WAXD spectra of PP with the different WBG content.

It can be seen form Figure 1 that when the WBG content is $0.2 \mathrm{phr}$, the peak intensity at $2 \theta=16.1^{\circ}$ decreases sharply with increasing AA-RCC, while the peak intensity at $2 \theta=16.1^{\circ}$ increases. As reported in Table 2, quantitative analysis shows that the $\beta_{1}$ crystal content falls to lowest value of 0.55 , and the $\beta_{2}$ crystal content increases from $0.26 \%$ to 0.63 . In Figure 2 , when the AA-RCC content remains constant (4 phr), the peak intensity at $2 \theta=16.1^{\circ}$ firstly increases and afterwards decreases with increasing WBG, and the $\beta_{1}$ crystal content decreases from 0.70 to 0.49 . However, the peak intensity at $2 \theta=16.9^{\circ}$ decreases sharply but peak at $2 \theta=21.3^{\circ}$ increases, indicating the emergence and increase of $\beta_{2}$ crystal content. There is no doubt that WBG and AA-RCC act with mutual inhibition effect in the crystallization of $\mathrm{PP}$ matrix and the effect increases with increasing content of WBG. Moreover, the mutual inhibition effect induces the growth of $\beta_{2}$ crystal.

3.2. Nonisothermal Crystallization and Melting Behavior Characterization. Figure 3 presents the crystallization ((a) and (c)) and melting ((b) and (d)) DSC curves of WBG/AA$\mathrm{RCC} / \mathrm{PP}$. The corresponding data is listed in Table 3. It is known that the crystallization peak temperature $\left(T_{\mathrm{cp}}\right)$ is $118 \sim 119^{\circ} \mathrm{C}[9,13]$. When $0.2 \mathrm{phr}$ WBG or $4 \mathrm{phr}$ AA-RCC is added to PP, either of the DSC curves has a single peak and $T_{\mathrm{cp}}$ is $126.81^{\circ} \mathrm{C}$ and $123.89^{\circ} \mathrm{C}$, respectively. When the content of WBG remains at $0.2 \mathrm{phr}$ level, with increasing AA-RCC, two peaks emerge in the curve of composites. The peak at low temperature is for $\beta$ crystal and the other at higher temperature for $\alpha$ crystal. When the content of AA-RCC remains at $4 \mathrm{phr}$ level, with increasing WBG, one of the two peaks gradually disappears resulting in a single peak at $118.54^{\circ} \mathrm{C}$. This indicates that WBG and AA-RCC affect the nucleating of PP and promote its crystallization. With the increasing content of WBG, a highly effective nucleating agent of $\beta$ crystal, the number of crystal nucleus, and crystallization rate increase, resulting in the increase of peak area of $\beta$ crystal [12].

Figures 3(b) and 3(d) show the melting curves of composites and relevant data are listed in Tables 2 and 3. According to DSC curve 2-1, when AA-RCC was added to PP, the melting curve has a single peak and $T_{m}$ is $161.78^{\circ} \mathrm{C}$. However, with only WBG being added to PP, the DSC curve 1-1 has two peaks and the crystallization peak temperatures are $152.38^{\circ} \mathrm{C}$ and $167.23^{\circ} \mathrm{C}$, respectively. When both WBG and AA-RCC were added to $\mathrm{PP}$, the curves of ternary composites have three peaks and their peak temperatures are $130^{\circ} \mathrm{C}, 149^{\circ} \mathrm{C}$, and $162^{\circ} \mathrm{C}$, respectively. It is also noted that the three peaks move to lower temperature and their peak areas increase with 


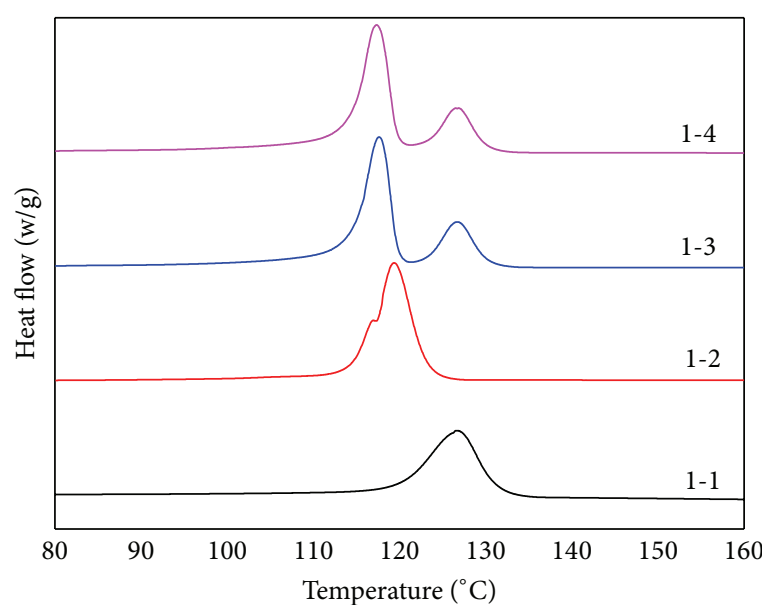

(a)

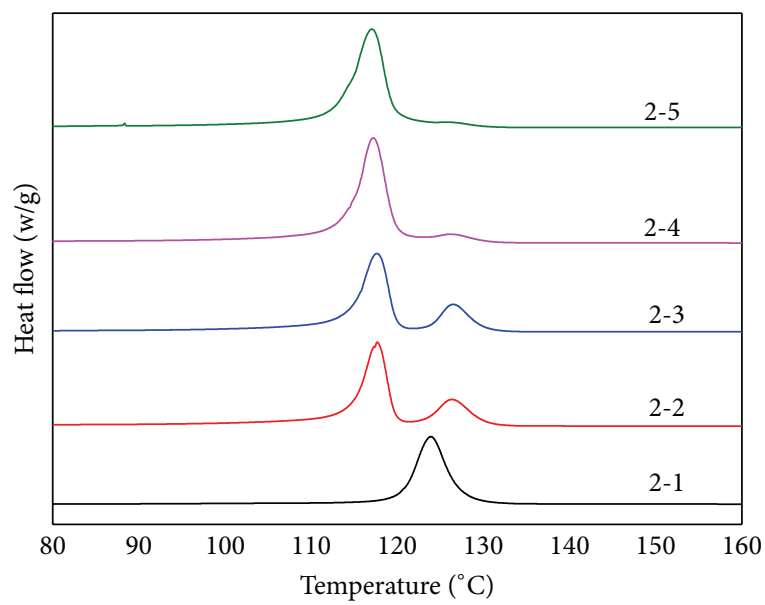

(c)

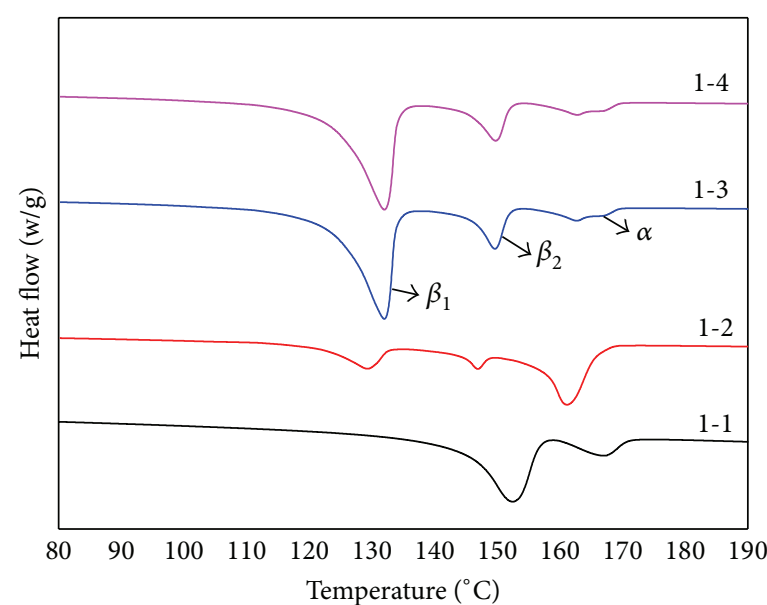

(b)

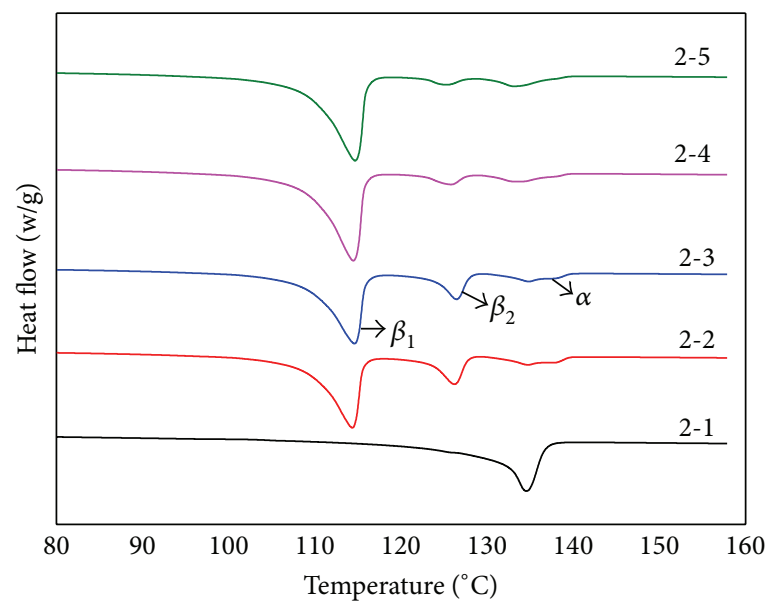

(d)

FIGURE 3: DSC crystallization ((a) and (c)) and melting ((b) and (d)) curves of WBG/AA-RCC/PP.

increasing content of WBG and AA-RCC. It is known that the melting peak of $\alpha$ crystal appears at a temperature range from $160^{\circ} \mathrm{C}$ to $170^{\circ} \mathrm{C}$, while it appears at a lower temperature for $\beta$ crystal [13]. There are two kinds of $\beta$ crystal melting peaks for WBG/AA-RCC/PP composites according to Figures 3(b) and $3(\mathrm{~d})$. The peak at lower temperature was attributed to $\beta_{1}$ crystal and the other peak at higher temperature to the recrystallization melting peak of $\beta_{1}$ and $\beta_{2}$ crystal [14]. From Figures $3(\mathrm{~b})$ and $3(\mathrm{~d})$, it is clear that the crystallization peak temperatures of $\beta_{1}$ and $\beta_{2}$ crystal vary remarkably. The peak area of $\beta_{1}$ crystal decreases gradually with increasing content of WBG and AA-RCC. It could be concluded that the two peaks suggest two kinds of crystals which might be assigned to (301) lattice plane of $\beta_{1}$ crystal and (300) lattice plane of $\beta_{2}$ crystal. These results are in accord with XRD analysis.

3.3. Crystal Morphology of WBG/AA-RCC/PP by POM. Figure 4 shows the POM micrographs of $0.2 \mathrm{phr} / \mathrm{WBG} / 4 \mathrm{phr}$ $\mathrm{AA}-\mathrm{RCC} / \mathrm{PP}$ at $130^{\circ} \mathrm{C}$. Just as shown in Figure $4(\mathrm{~b})$, line shape crystal nucleus emerges at the beginning of crystallization. The line shape crystal nucleus becomes thicker gradually by growing towards outside symmetrically over time, resulting with a tightly arranged network structure with uniform density. Because $\alpha$ crystal occurs before $\beta$ crystal, AA-RCC promotes the heterogeneous nucleation of $\alpha$ crystal and RCC offers a template for $\alpha$ crystal growth along a specific lattice plane and promotes the epitaxial crystallization of PP matrix as shown in XRD analysis, while the specific arranged $\alpha$ crystal could induce the formation of $\beta$ column crystal. When spherocrystal grows faster than column crystal, $\alpha$ crystal gradually transforms into $\beta$ crystal [15]. Therefore, it finally comes out to be $\beta$ crystal with a tightly arranged network structure.

\section{Conclusions}

In this paper, the ternary composite materials of WBG/AA$\mathrm{RCC} / \mathrm{PP}$ were prepared and their crystallization behaviors were investigated by XRD and DSC. WBG and AA-RCC promote the formation of $\beta$ crystal and $\beta_{2}$ crystal increases but $\beta_{1}$ crystal decreases, suggesting that there is a competition between $\alpha$ and $\beta$ crystal growth which is in favor of the formation of $\beta$ crystal. 


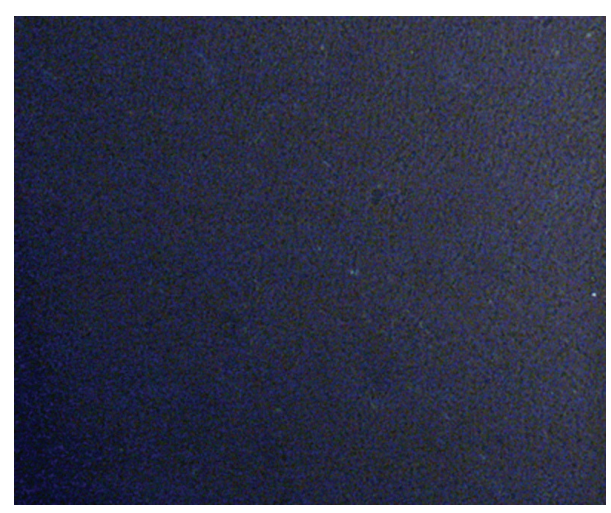

(a) $(5 s)$

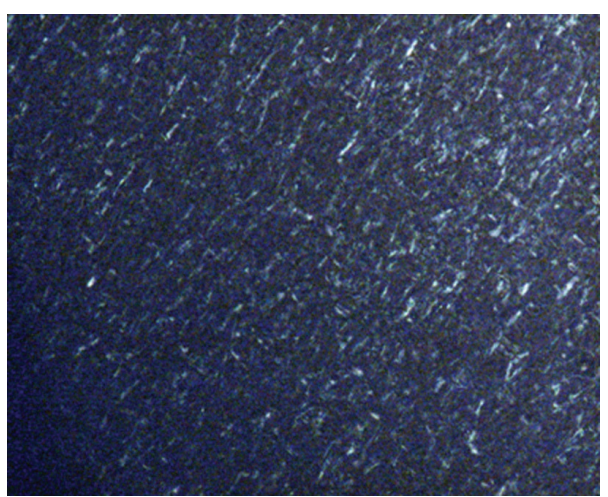

(c) $(30 \mathrm{~s})$

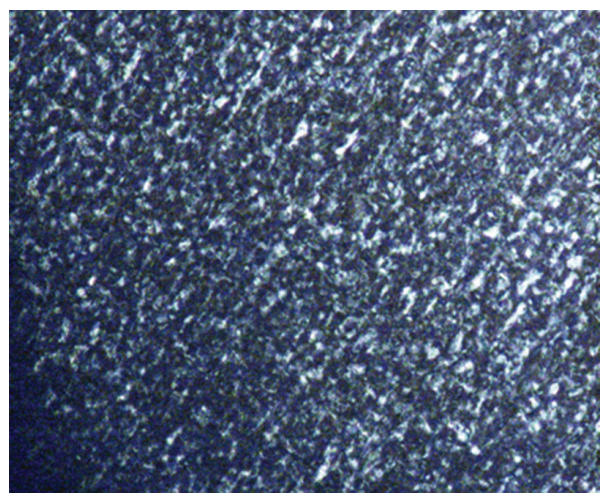

(e) $(5 \mathrm{~m})$

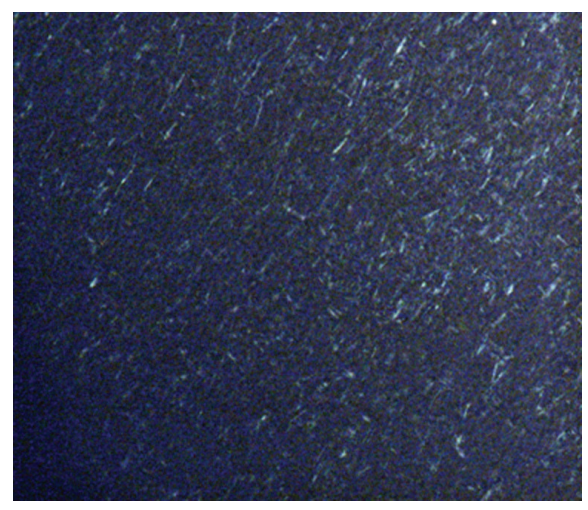

(b) $(10 \mathrm{~s})$

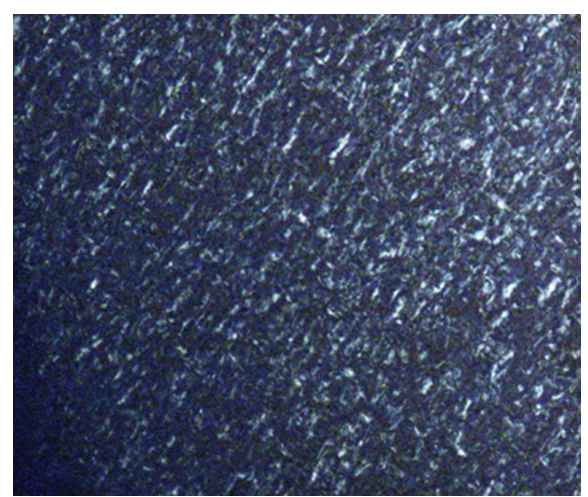

(d) $(1 \mathrm{~m})$

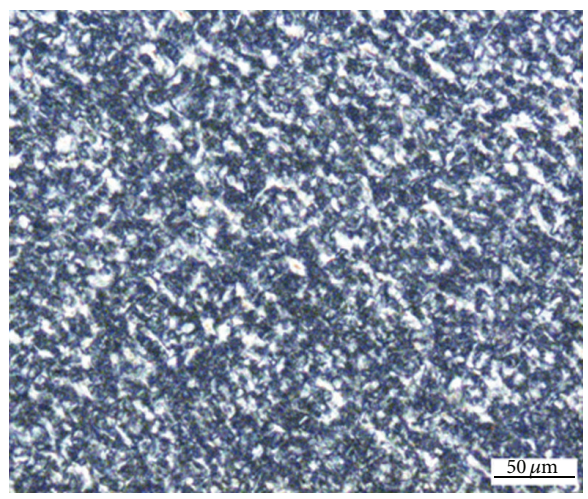

(f) $(30 \mathrm{~m})$

FIgURE 4: POM micrographs of WBG/AA-RCC/PP.

\section{Conflict of Interests}

The authors declare that there is no conflict of interests regarding the publication of this paper.

\section{Acknowledgments}

This study was financially supported by (a) the Natural Science Foundation of Chongqing Municipal Science and Technology Commission, China (Grant no. CSTC2013JCYJA50029), (b) the Local Fund for Chongqing University of Arts and Sciences (Grant no. R2012CH08), (c) the Opening-project Fund for Chongqing Key Laboratory of Micro/Nano-Materials Engineering and Technology (Grant no. KFJJ1209), and the graduate research project for Chongqing University of Arts and Sciences (Grant no. M2013ME04).

\section{References}

[1] C. Grein, "Toughness of neat, rubber modified and filled $\beta$ nucleated polypropylene: from fundamentals to applications," Advances in Polymer Science, vol. 188, pp. 43-104, 2005.

[2] D. Byelov, P. Panine, K. Remerie, E. Biemond, G. C. Alfonso, and W. H. de Jeu, "Crystallization under shear in isotactic 
polypropylene containing nucleators," Polymer, vol. 49, no. 1314, pp. 3076-3083, 2008.

[3] L. Xu, K. Xu, D. Chen, Q. Zheng, F. Liu, and M. Chen, “Thermal behavior of isotactic polypropylene in different content of $\beta$ nucleating agent," Journal of Thermal Analysis and Calorimetry, vol. 96, no. 3, pp. 733-740, 2009.

[4] D. Libster, A. Aserin, and N. Garti, "Advanced nucleating agents for polypropylene," Polymers for Advanced Technologies, vol. 18, no. 9, pp. 685-695, 2007.

[5] J. Kang, B. Wang, H. Peng et al., "Investigation on the dynamic crystallization and melting behavior of $\beta$-nucleated isotactic polypropylene with different stereo-defect distributionthe role of dual-selective $\beta$-nucleation agent," Polymers for Advanced Technologies, vol. 25, no. 1, pp. 97-107, 2014.

[6] H. U. Zaman, P. D. Hun, R. A. Khan, and K. Yoon, “Comparison of effect of surface-modified micro-/nano-mineral fillers filling in the polypropylene matrix," Journal of Thermoplastic Composite Materials, vol. 26, no. 8, pp. 1100-1113, 2013.

[7] J. Ding, J. Shangguan, W. Ma, and Q. Zhong, "Foaming behavior of microcellular foam polypropylene/modified nano calcium carbonate composites," Journal of Applied Polymer Science, vol. 128, no. 6, pp. 3639-3651, 2012.

[8] J. Ding, W. Ma, F. Song, and Q. Zhong, "Effect of nano-Calcium Carbonate on microcellular foaming of polypropylene," Journal of Materials Science, vol. 48, no. 6, pp. 2504-2511, 2013.

[9] Z. Zhang, C. Wang, J. Zhang, and K. Mai, “The $\beta$-nucleation of polypropylene random copolymer filled by nano- $\mathrm{CaCO}_{3}$ supported $\beta$-nucleating agent," Journal of Thermal Analysis and Calorimetry, vol. 109, no. 3, pp. 1587-1596, 2012.

[10] Y. Lin, H. Chen, C.-M. Chan, and J. Wu, "High impact toughness polypropylene/ $\mathrm{CaCO}_{3}$ nanocomposites and the toughening mechanism," Macromolecules, vol. 41, no. 23, pp. 9204-9213, 2008.

[11] L. Li and Q. Dou, "Effect of malonic acid treatment on crystal structure, melting behavior, morphology, and mechanical properties of isotactic polypropylene/nano- $\mathrm{CaCO}_{3}$ composites," Journal of Macromolecular Science Part B: Physics, vol. 50, no. 5, pp. 831-845, 2011.

[12] W. Xiao, P. Wu, J. Feng, and R. Yao, "Influence of a novel $\beta$ nucleating agent on the structure, morphology, and nonisothermal crystallization behavior of isotactic polypropylene," Journal of Applied Polymer Science, vol. 111, no. 2, pp. 1076-1085, 2009.

[13] Z. Lin, C. Chen, Z. Guan et al., "The $\beta$-nucleated ternary composites of polypropylene/nano- $\mathrm{CaCO}_{3} /$ short poly(ethyleneterephthalate) fiber," Journal of Thermal Analysis and Calorimetry, vol. 114, no. 1, pp. 229-237, 2013.

[14] Z. Zhang, C. Chen, C. Wang, J. Guo, and K. Mai, "Nonisothermal crystallization kinetics of isotactic polypropylene nucleated with a novel supported $\beta$-nucleating agent," Journal of Thermal Analysis and Calorimetry, vol. 103, no. 1, pp. 311-318, 2011.

[15] J. Varga and J. Karger-Kocsis, "Rules of supermolecular structure formation in sheared isotactic polypropylene melts," Journal of Polymer Science Part B: Polymer Physics, vol. 34, no. 4, pp. 657-670, 1996. 

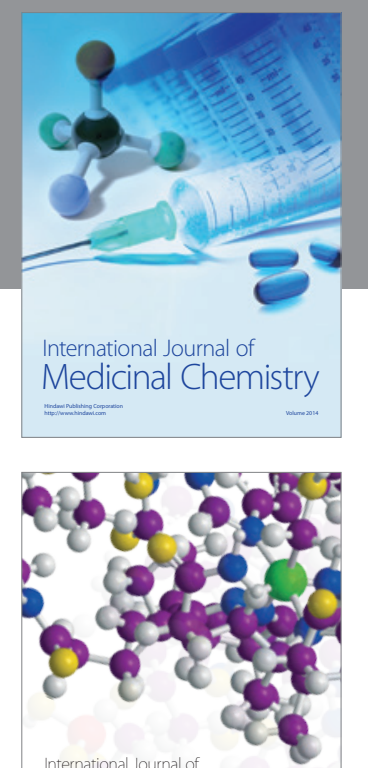

\section{Carbohydrate} Chemistry

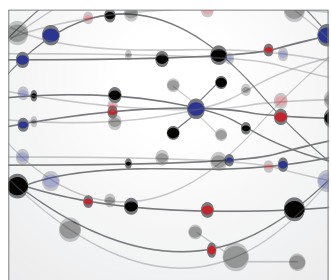

The Scientific World Journal
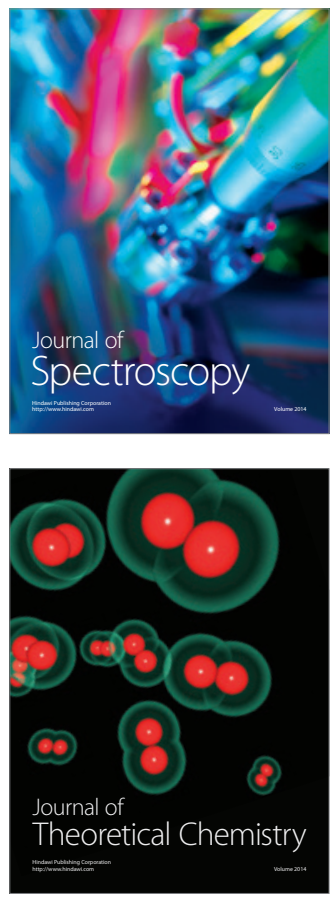
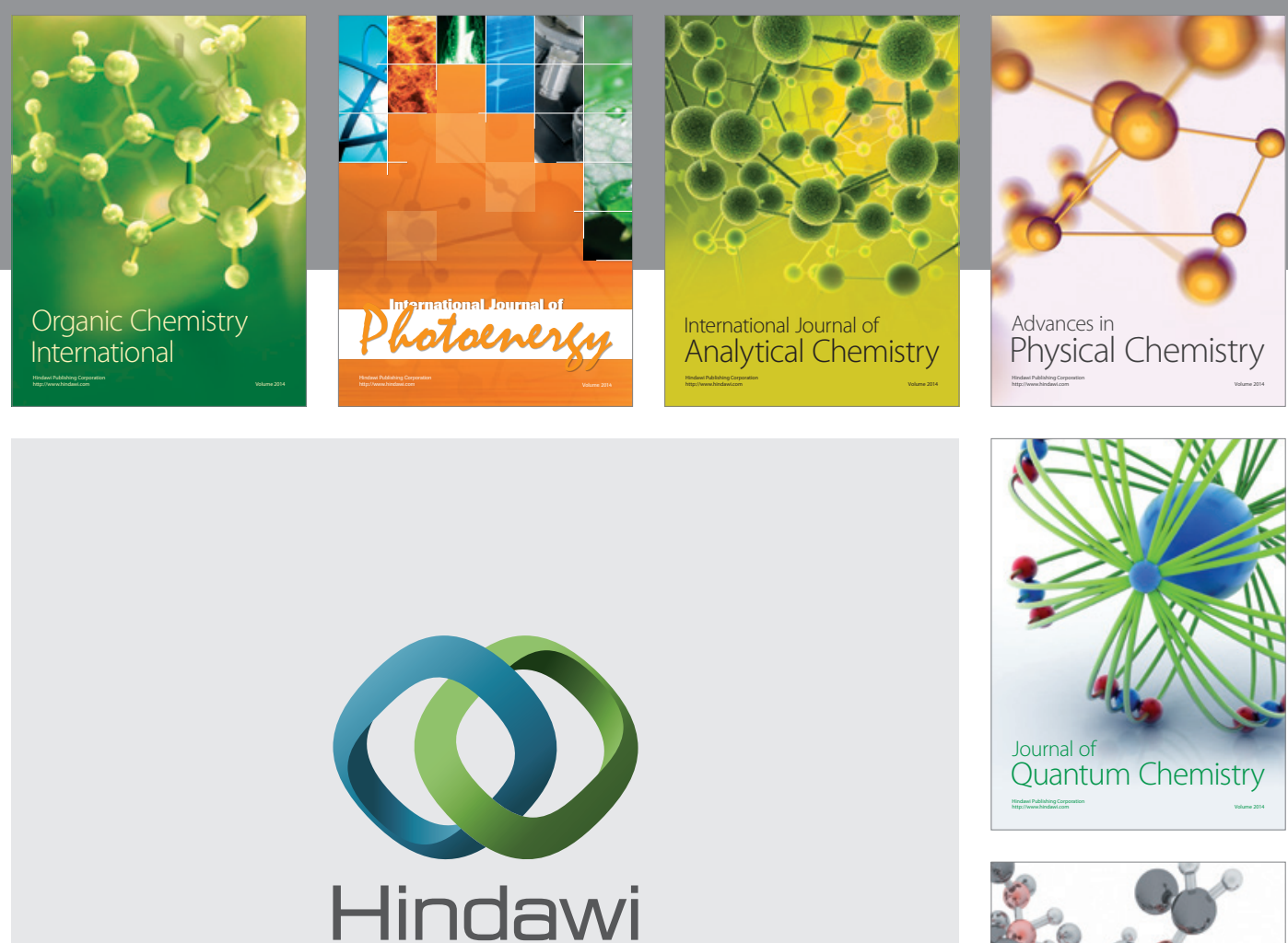

Submit your manuscripts at

http://www.hindawi.com

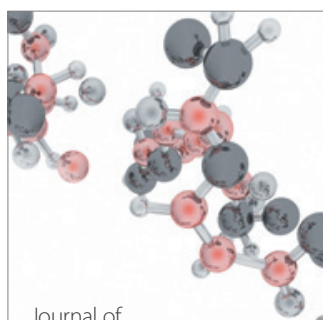

Analytical Methods

in Chemistry

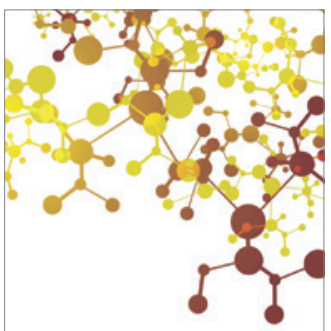

Journal of

Applied Chemistry

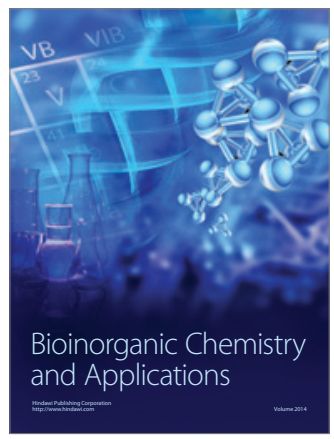

Inorganic Chemistry
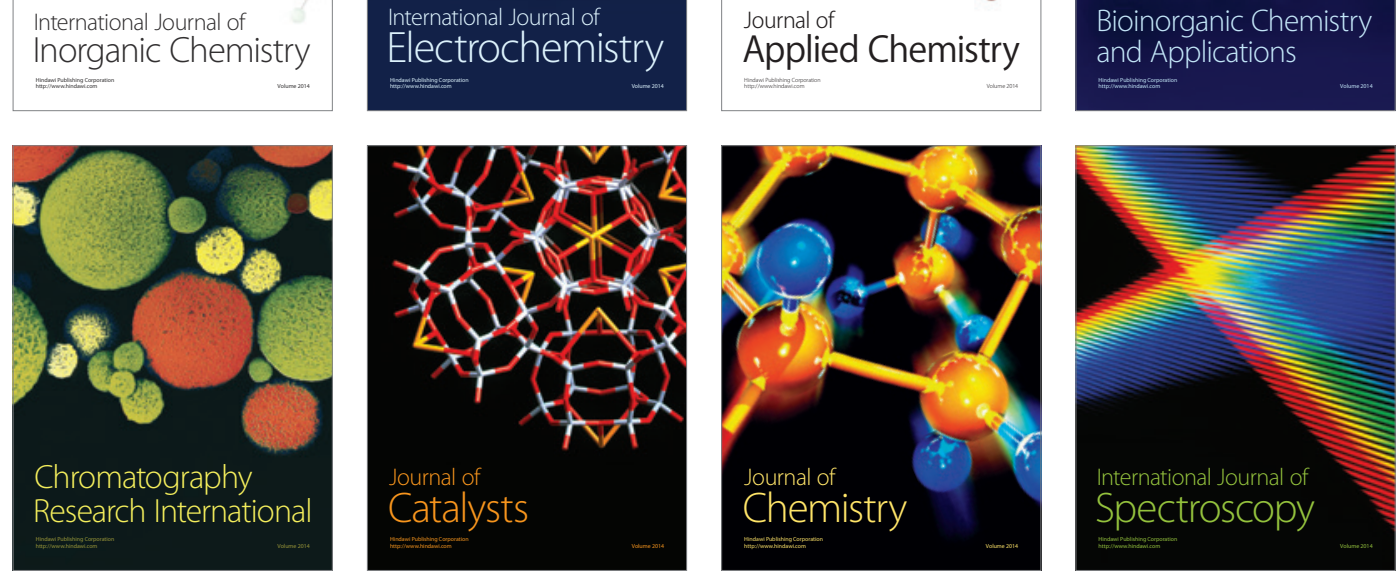